\title{
A New Tool for the Detection of Horsemeat Adulteration in Raw Meat
}

\section{Ricardo Adriano Dorledo de Faria ${ }^{1,2}$, Iden $\mathrm{H}^{2}$, Bharucha $\mathrm{E}^{2}$, Lins VFC1, Younès Messaddeq ${ }^{2,3 *}$, Matencio $\mathrm{T}^{4}$ and Heneine LGD $^{5}$}

${ }^{1}$ Department of Chemical Engineering, Universidade Federal de Minas Gerais (UFMG), Brazil

${ }^{2}$ Center for Optics, Photonics and Lasers (COPL), Université Laval, Canada

${ }^{3}$ Institute of Chemistry, UNESP, Araraquara, São Paulo, Brazil

${ }^{4}$ Department of Chemistry, Universidade Federal de Minas Gerais (UFMG), Brazil

${ }^{5}$ Department of Applied Immunology, Fundação Ezequiel Dias (FUNED), Brazil

\section{Abstract}

This work deals with the development of an impedimetric immunosensor sensitive to horse immunoglobulin $\mathrm{G}$. The biosensing platform involve the electrodeposition of polyaniline onto screen-printed carbon electrode as electrochemical transducer matrix. Cyclic Voltammetry and Scanning Electron Microscopy were used to monitor the formation of the recognition layer through the immobilization of anti-horse IgG antibodies on the conductive polymer. Electrochemical Impedance Spectroscopy (EIS) was performed to test the specific detection of horse serum in PBS buffer, indicating that the immunosensor was sensitive to the target analyte and without any response to heterologous sera (swine and bovine). The constructed sensors were first tested with PBS homogenates of commercial samples of raw ground horsemeat, pork and beef diluted at $10^{-5}, 10^{-4}$ and $10^{-3} \% \mathrm{w} / \mathrm{v}$ in PBS. The total time for performing the test was approximately 72 minutes and a selective response of the device is obtained with a $0.004 \%$ limit of detection.

Keywords: Horsemeat adulteration; Immunosensor; Electrochemical Impedance Spectroscopy

\section{Introduction}

Food fraud is an illegal intentional practice that involves mainly the addition of adulterant-substances, counterfeiting and the mislabelling of food products [1]. Meat products are a special target for adulteration, in which the manufacturers replace high-cost species for low-valued ones aiming economic gain, because of its traditional presence in human diet as a major protein source [2]. The magnitude of the impact caused by this criminal act reflects on high economic losses, consumers' confidence and health risks (since the fraudulent substance can be an allergen for a population group) [3-5].

In January 2013, the horsemeat scandal (also named "horsegate") in Europe drew great attention worldwide to the importance of meat adulteration screening. In this incident, the Food Safety Authority of Ireland denounced the presence of undeclared horsemeat in extensive amount of beef and pork products of European suppliers [6]. Horsemeat is used instead other meats due to its low-cost of production (e.g. the price per ton of horsemeat is estimated to be approximately USD 1,300, while the same amount of beef cost around USD 5,300). In most of cases, horses are slaughtered at the end of their lives or when they suffer some diseases, when the market do not recognize potential economic application or nutritional value on their meat [7]. As consequences, the global market suffered a huge economic recession, bovine products underwent a price increase of $45 \%$ between 2008 and 2012 and the sales of ready-made beef meals significantly decreased in the same year [1].

In this context, many techniques have been developed for authentication of meat products based on their physical, chemical, optical and biochemical properties, such as ELISA, chromatography, DNA-based assays, mass spectrometry and fluorescence spectroscopy [8-10]. Despite efficient and sensitive, these methods are laborious, expensive, time-consuming, sophisticated, demand highly trained staff and are difficult to use in online applications [11-13].

In this regard, immunosensors based on the Electrochemical Impedance Spectroscopy (EIS) are promising candidates for meat speciation. The impedimetric immunosensors are a subcategory of biosensors that combine the great specificity of the antibody-antigen bonds with the high sensitivity of a non-destructive electrochemical technique [14]. Furthermore, among the advantages of the technology of biosensors, the easiness-to-perform, not requiring highly specialized staff, possibility of miniaturization, possibility of performing real-time detection and the low cost are particularly very propitious features for application in food authenticity [15-17].

A typical impedimetric immunosensor consists of a conductive transducer matrix onto which a layer containing immobilized antibodies as elements of recognition will bind a target analyte, causing changes in the dielectric properties at the interface between electrode and electrolyte $[18,19]$. Herein, as a strategy for horsemeat adulteration screening, we immobilized goat anti-horse Immunoglobulin G (IgG) on the surface of screen-printed carbon electrodes (SPCEs) containing conductive polyaniline (PANI) to monitor the variations of impedance caused by its exposition to the target analyte.

\section{Materials and Methods}

\section{Apparatus and chemicals}

Triplicate electrochemical tests were carried out using a Princeton Applied Research VersaSTAT 3 potentiostat/galvanostat (Ametek Scientific Instruments, Canada) interfaced with the VersaStudio software. The measurements were performed using SPCEs immersed in an electrolyte containing $0.01 \mathrm{M}$ PBS buffer $(\mathrm{pH} 7.4)$ and $0.1 \mathrm{M} \mathrm{KCl}$ at room temperature. The SPCEs were purchased from Pine Research Instrumentation and are consisted of a carbon working electrode

${ }^{*}$ Corresponding author: Younès Messaddeq, Center for Optics, Photonics and Lasers (COPL), Université Laval, Québec, Canada, Tel: 418 656-5338; E-mail: younes.messaddeq@copl.ulaval.ca

Received November 13, 2018; Accepted December 29, 2018; Published December 31, 2018

Citation: de Faria RAD, Iden H, Bharucha E, Lins VFC, Messaddeq Y et al. (2018) A New Tool for the Detection of Horsemeat Adulteration in Raw Meat. J Biosens Bioelectron 9: 264. doi: 10.4172/2155-6210.1000264

Copyright: ( $) 2018$ de Faria RAD, et al. This is an open-access article distributed under the terms of the Creative Commons Attribution License, which permits unrestricted use, distribution, and reproduction in any medium, provided the original author and source are credited. 
(model RRPE1002C, $5 \times 4 \mathrm{~mm}$ ), carbon as a counter-electrode and an $\mathrm{Ag} / \mathrm{AgCl}$ reference electrode.

Ultraviolet-visible spectroscopy (UV-VIS) was performed using a Cary series UV-VIS-NIR spectrophotometer (Agilent Technologies). The scanning electron microscopy (SEM) images were recorded using a Quanta 3D FEG microscope.

Phosphate saline buffer (PBS), glutaraldehyde (25\%) and bovine serum were purchased from Sigma-Aldrich (USA). Potassium chloride was obtained from Fisher Scientific (Belgium). Aniline (purity $\geq 99 \%$ ) was acquired from Alfa Aesar and sulfuric acid 98\% was purchased from Anachemia (Canada). Lyophilized whole horse serum, whole pig serum and goat anti-horse polyclonal immunoglobulin G (IgG) were purchased from MP Biomedicals (Fisher Scientific, Canada). Casein of high purity grade was purchased from Amresco (USA). Ground horsemeat, pork and beef were purchased from the local market of Quebec City (Quebec, Canada). All solutions were prepared with ultrapure deionized water with an $18 \mathrm{M} \Omega . \mathrm{cm}$ resistivity.

\section{Functionalization of the SPCEs for recognition of horse IgG}

Prior to functionalization, the SPCEs were treated in $0.05 \mathrm{M}$ sulfuric acid by cycling potential from -2.5 to $+2.5 \mathrm{~V}$ vs $\mathrm{Ag} / \mathrm{AgCl}$ at $50 \mathrm{mV} \cdot \mathrm{s}^{-1}$. This method is an effective, simple and cheap procedure to remove organic contaminants from the carbon ink, improving its electroactivity and increasing its surface roughness [20].

Afterwards, PANI was electrodeposited on the pretreated SPCE to improve its electrical conductivity. The polymerization was carried out by Cyclic Voltammetry (CV), scanning 15 cycles from -0.4 to 1.0 $\mathrm{V}$ vs $\mathrm{Ag} / \mathrm{AgCl}$ at $50 \mathrm{mV} \cdot \mathrm{s}^{-1}$ in an aqueous solution of $0.1 \mathrm{M}$ aniline containing $0.1 \mathrm{M} \mathrm{H}_{2} \mathrm{SO}_{4}$ [21]. We studied various concentrations of aniline to obtain PANI as an electrochemical transducer matrix for application in an immunosensor and we found that $0.1 \mathrm{M}$ is an ideal concentration because it improves the electroactivity of the electrode and consequently the sensitivity of the device.

Subsequently, $30 \mu \mathrm{L}$ of an aqueous solution of $1 \% \mathrm{v} / \mathrm{v}$ glutaraldehyde was deposited on the working electrode, which was kept in this solution for $1 \mathrm{~h}$. After, the SPCEs were washed with $0.01 \mathrm{M} \mathrm{PBS} \mathrm{(} \mathrm{pH}$ 7.4) to remove the nonbonding aldehydes. Then, a $100 \mu \mathrm{g} \cdot \mathrm{mL}^{-1}$ solution of antihorse antibodies was added to the surface for $1 \mathrm{~h}$, when the electrode was newly washed with PBS. Finally, they were incubated in a $1 \% \mathrm{w} / \mathrm{v}$ casein solution in $0.01 \mathrm{M}$ PBS to block possible remaining reactive sites present on the surface, avoiding unspecific cross-reactions.

\section{Characterization of the biosensor}

$\mathrm{CV}$ was used to the electrochemical monitoring of the functionalization steps to obtain the biosensor, which was performed as a single cycle from -0.4 to $1.0 \mathrm{~V} v s \mathrm{Ag} / \mathrm{AgCl}$ at $50 \mathrm{mV} . \mathrm{s}^{-1}$. The structural modifications on the SPCE surface due to functionalization were also inspected by SEM with an acceleration voltage of $5 \mathrm{kV}$. Energy dispersive X-ray spectroscopy (EDX) coupled with SEM equipment was recorded to inspect the effect of the acid pre-treatment in the SPCE.

\section{Electrochemical sensing of horse IgG}

Detection of horse IgG in buffer solution: Horse serum was diluted in $0.01 \mathrm{M}$ PBS ( $\mathrm{pH}$ 7.4) to obtain the homologous analyte solutions at the following concentrations: 1 pg.mL $\mathrm{mL}^{-1}, 10 \mathrm{pg} \cdot \mathrm{mL}^{-1}, 100$ pg. $\mathrm{mL}^{-1}, 1$ ng. $\mathrm{mL}^{-1}, 100$ ng. $\mathrm{mL}^{-1}$ and $1 \mu \mathrm{g} \cdot \mathrm{mL}^{-1}$. The biosensor was exposed to $30 \mu \mathrm{L}$ of the mentioned solutions during 20 minutes. After each incubation, the biosensor was gently washed with $0.01 \mathrm{M}$ PBS in order to remove unbound and physically adsorbed molecules from the electrode surface.

Electrochemical Impedance Spectroscopy (EIS) was performed in $0.01 \mathrm{M}$ PBS containing $0.1 \mathrm{M} \mathrm{KCl}$ as supporting electrolyte. A perturbation amplitude of $10 \mathrm{mV}$ around the Open Circuit Potential (OCP) was applied in a range of frequencies varying from $10 \mathrm{kHz}$ to 100 $\mathrm{mHz}$. The EIS data were fitted to an electrical equivalent circuit with the commercial software Zview (Scribner and Associates, version 2.9b).

To test the selectivity of the biosensor, the impedance response with other meat species was also investigated. For this purpose, the device was incubated in heterologous swine and bovine sera at the same concentrations and experimental conditions.

Detection of horse IgG in commercial raw meats: In order to evaluate the capability of the biosensor to recognize the target analyte in real samples, the device was exposed to horsemeat, pork and beef. To accomplish this, the commercial ground meats were diluted in $0.01 \mathrm{M}$ PBS ( $\mathrm{pH} 7.4$ ) to the final concentration of $1 \% \mathrm{w} / \mathrm{v}$. Each buffered solution was then homogenized for 30 minutes by using a VWR vortex mixer. Then, the solutions were centrifuged at $10,000 \mathrm{xg}$ for 15 minutes at room temperature. The supernatant was collected and filtered using a $0.45 \mu \mathrm{m}$ filter.

To estimate the concentration of proteins $[\mathrm{P}]$ extracted from the horsemeat, pork and beef by using the previous protocol and based on equation 1 [22], the absorbance of each sample was measured by UV-V is spectroscopy at $280 \mathrm{~nm}\left(\mathrm{~A}_{280}\right)$ and $260 \mathrm{~nm}\left(\mathrm{~A}_{260}\right)$ with a path length fixed at $1 \mathrm{~cm}$.

$$
[\mathrm{P}]=1.55 \mathrm{~A}_{280}-0.76 \mathrm{~A}_{260}
$$

The centrifuged and filtered samples were diluted 1,000;10,000 and 100,000 times in $0.01 \mathrm{M}$ PBS. To perform the detection tests, $30 \mu \mathrm{L}$ of meat solution was dropped on the working electrode of the biosensors and the impedance measurement was performed after 20 minutes incubation period.

\section{Results and Discussion}

\section{Characterization of the immunosensor by $\mathrm{CV}$}

$\mathrm{CV}$ was employed to inspect the interfacial electrochemical characteristics of the SPCE during the functionalization. Figure 1

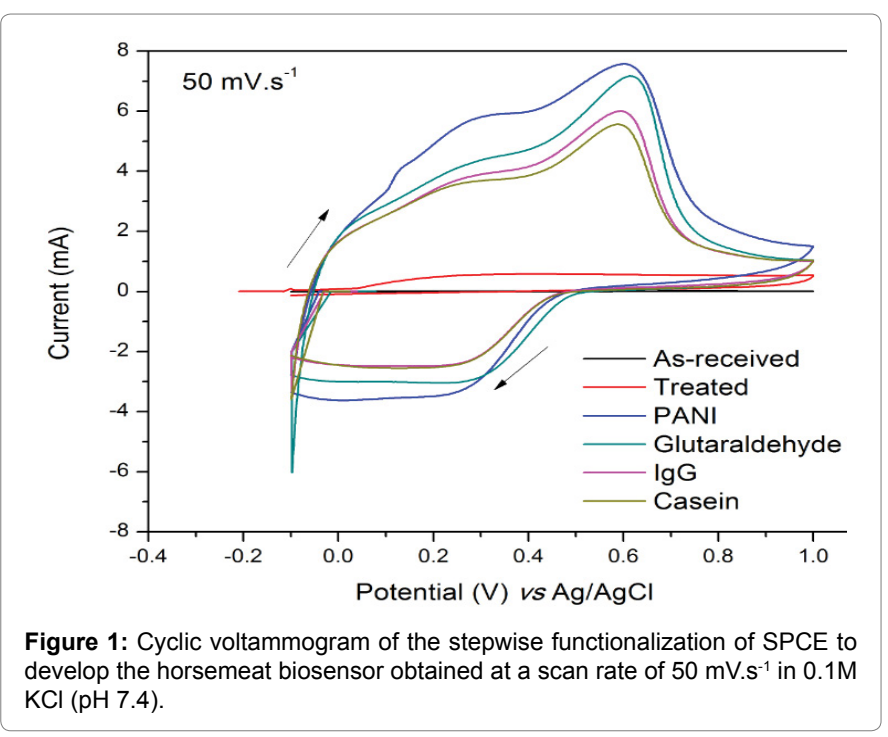


shows that the electrode suffered significant changes due to each step of its modification. The as-received SPCE exhibited a very low value of current due to the low electroactivity of carbon. After treating the electrode via cycling in sulfuric acid at extreme potentials, the material is activated by the removal of organic compounds of its surface. The application of high anodic and cathodic potentials on the electrode provokes the oxygen and hydrogen evolve from the carbon surface improving its heterogeneous electron transfer kinetics [20,23], which causes an increase of its electrical charge.

After the electropolymerization of PANI, the electron transfers remarkably increased, due to its high electroactivity. The PANI conjugated backbone structure comprised of alternating single and double bonds along its chain facilitates the electron transfer thorough the extended $\pi$ network and provides its semiconductor features [24]. Furthermore, the redox peaks observed in the voltammogram can be associated to the different oxidation states of PANI. Leucoemeraldine is the fully reduced state, pernigraniline is the fully oxidized state and emeraldine corresponds to the partially oxidized form, whose doped state (emeraldine salt) is the most interesting one for electrochemical applications because it is the only electrically conducting phase [25].

When PANI was exposed to the glutaraldehyde solution, the redox peaks height decreased due to the crosslinking reaction between the amino terminal groups from the polymer and the $-\mathrm{CHO}$ group of the aldehyde [26]. Next, the exposition to antibodies and casein caused new decreases of the overall voltammetric signal, because of the insulator behavior of these organic compounds, which block the path of electron transport and hinder the faradaic reaction rates $[27,28]$.

\section{Characterization of the immunosensor by SEM-EDX}

The morphology of the SPCE is a very important parameter for developing the biosensor, mainly because it is related to the available surface area for antibody binding, consequently affecting the performance of the device.

Figure 2a shows that the bare SPCE has porous with higher roughness and contains some isolated graphite flakes on the surface. After the acid treatment (Figure 2b), the electrode seemed to suffer a subtle removal of the small particles with consequent greater exposition of graphite.

The EDX spectrum shown in Figure 3 indicates that the SPCE is mainly composed of carbon, oxygen, chlorine and sodium. The presence of sodium and chlorine are probably related to the insertion of additives in the carbon ink [29]. Despite the manufacturers do not provide details about ink composition due to proprietary information, it is known that it contains not only graphite but also solvents and some polymeric binders [30]. After the acid treatment, the main observed alteration was the introduction of hydroxyl groups on the SPCE surface due to the application of extreme potentials, which can be verified by the significantly increase of the oxygen peak.

Figure 4a depicts the morphology of PANI electrodeposited onto the treated SPCE, which is in agreement with the results reported by other authors [31,32]. The polymer was obtained as a spongy, porous and branched film with high surface area and interconnected fibers network. Although the glutaraldehyde attachment did not cause an obvious change in the electrode structure (Figure $4 \mathrm{~b}$ ), the immobilization of anti-horse IgG could be noted in Figure 4c. The attached antibodies were present as some small protein clusters on the PANI fibers, whose size could not be accurately measured since the length of an antibody is supposed to be around only $11 \mathrm{~nm}[33,34]$.

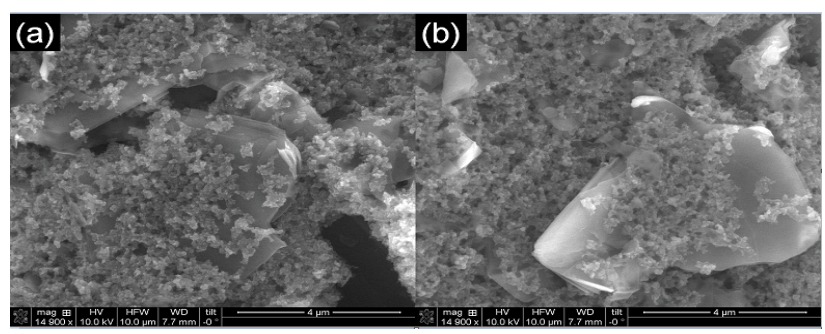

Figure 2: SEM image of the SPCE before (a) and after (b) acid treatment using $\mathrm{CV}$.

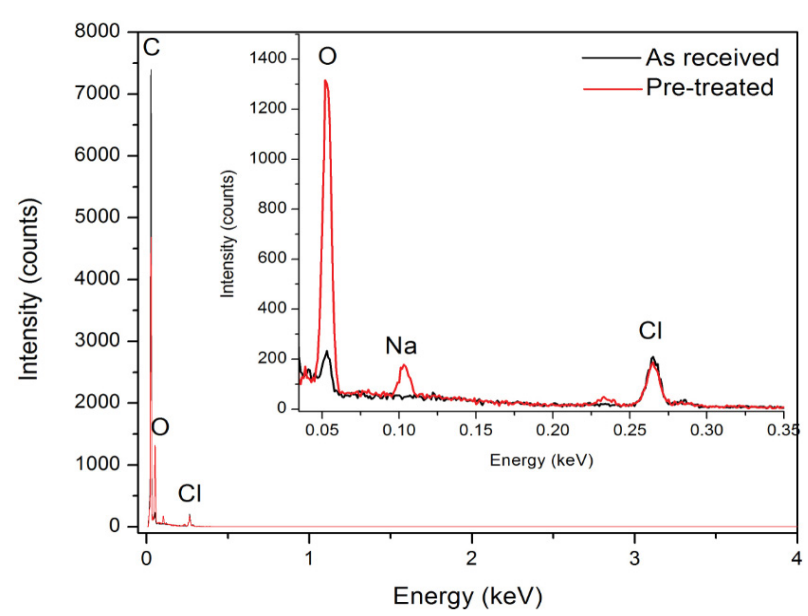

Figure 3: EDX spectrum of the SPCE before and after the acid treatment using $\mathrm{CV}$. The inset shows the spectrum in the lower energy region (up to $0.35 \mathrm{keV})$.

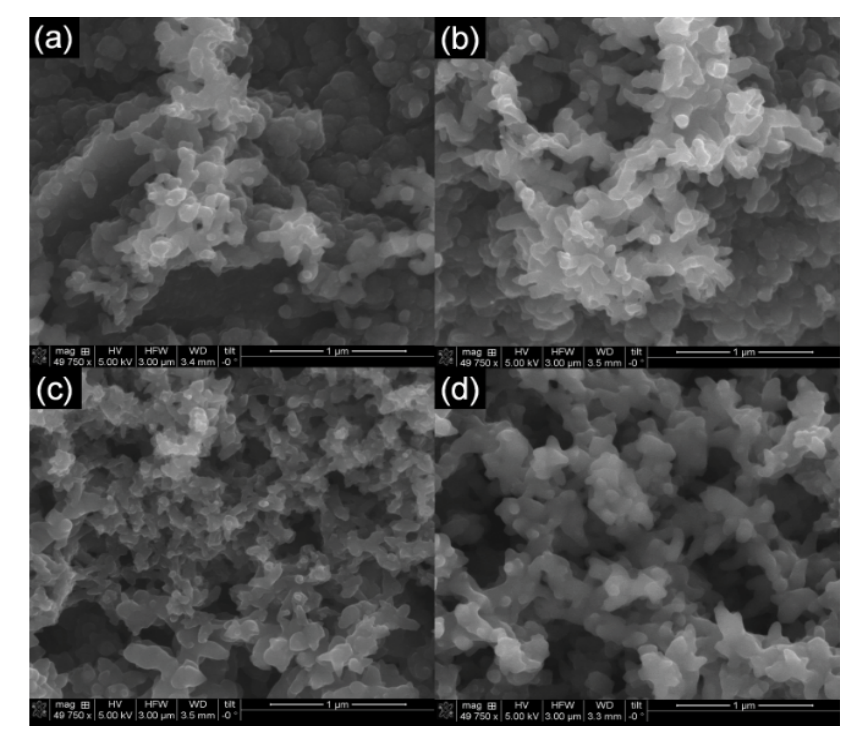

Figure 4: SEM images of the treated SPCE modified by the deposition of PAN (a), glutaraldehyde (b), anti-horse IgG (c) and casein (d).

Finally, it is shown in Figure 4d that the electrode containing casein became brighter and changed the texture of the material with respect to the previous step, confirming the efficiency of the blocking. EDX was not employed as a technique for studying the modifications caused 
in these functionalization steps because its depth resolution is not expected to provide enough information about the surface alterations caused by the biomolecules immobilization.

\section{Immunosensor padronization: horse serum IgG detection}

Aiming to assess the capability of the biosensor to detect the target analyte (horse IgG), it was assayed with horse serum at various concentrations. Figure 5 shows the impedance spectrum obtained before and after the exposure of the biosensor to the solutions containing horse serum diluted in PBS buffer. The Nyquist plot is a typical form to represent EIS data and it is represented as a correlation between the real (Z') and the imaginary (Z") impedances. In this type of representation, the semicircle diameter relates to the electron transfer limited processes and the linear part at the low frequencies region corresponds to diffusion-limited processes [35]. The interpretation of impedance plots provides useful information about interface properties of an electrode and allows inferring about the presence of adsorbed substances at the surface [36].

Briefly, it is possible to observe that the semicircle diameter increased with increasing horse serum concentration. However, to quantify the impedimetric response of an electrochemical system, the EIS data is generally fitted with an equivalent circuit comprising electrical elements such as resistors, capacitors and/or inductors. The inset in Figure 5 represents the equivalent circuit used to model the impedance data.

This model (Randles equivalent circuit) consists of an electrolyte resistance $(\mathrm{Re})$ in series with a constant phase element (CPE) associated in parallel with the pair charge transfer resistance $\left(\mathrm{R}_{\mathrm{ct}}\right)$ and Warburg impedance $(\mathrm{Zw})$. The $\mathrm{CPE}$ is used instead a pure capacitor due to the inhomogeneneity of the electrode surface, which can cause coupling of the solution resistance and the irregular distribution of the capacitance over the electrode [37]. The $\mathrm{R}_{\mathrm{ct}}$ is related to the semicircle diameter of the Nyquist plot and represents the barrier to the electron transfer over the conductive PANI transducer. This element is commonly monitored as a useful parameter to evaluate the performance of Faradaic biosensors because it is significantly affected by the interaction of antigen-antibody at the electrode surface [38-40]. In this work, the condition of chi-squared $\chi^{2}<10^{-3}$ [41-43] was employed as a criterion for validating the proposed Randles circuit, which was satisfied when fitting all the experimental measurements.

\section{Validation of impedance data by Kramer's-Kronig transform}

In order to validate EIS data, Kramer's-Kronig (K-K) transform was employed to evaluate whether the designed biosensor was affected by extrinsic factors. This method is based on the Linear Systems Theory, which examines if a certain system is sufficiently linear, causal and stable to confirm the robustness of the impedance result [44]. The $\mathrm{K}-\mathrm{K}$ method consists in calculating the values of $Z^{\prime}$ by means of the experimental Z" and the theoretical Z" values from the experimental Z' according to the respective equations 2 and 3, in which " $\omega$ " is the angular frequency of the input voltage.

$$
\begin{aligned}
& Z^{\prime}(\omega)=\frac{2}{\pi} \cdot \int_{0}^{\infty} \frac{\omega^{\prime} \cdot Z^{\prime \prime}\left(\omega^{\prime}\right)}{\omega^{2}-\omega^{\prime 2}} d \omega^{\prime} \\
& Z^{\prime \prime}(\omega)=\frac{-2}{\pi} \cdot \int_{0}^{\infty} \frac{\omega \cdot Z^{\prime}\left(\omega^{\prime}\right)}{\omega^{2}-\omega^{\prime 2}} d \omega^{\prime}
\end{aligned}
$$

Figure 6 presents the Bode diagram of the experimental EIS data

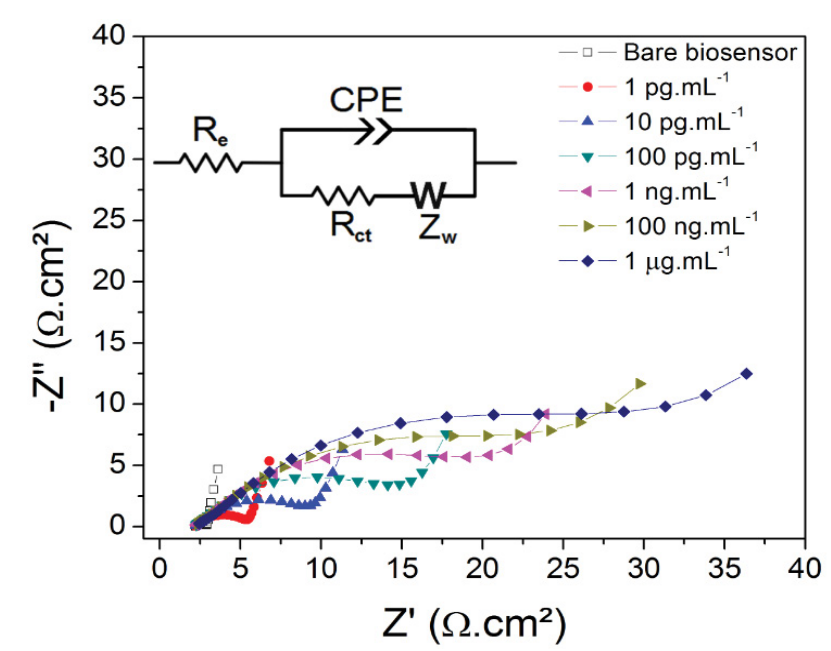

Figure 5: Nyquist plot of the immunosensor before and after the exposure to horse serum at various concentrations in PBS buffer.

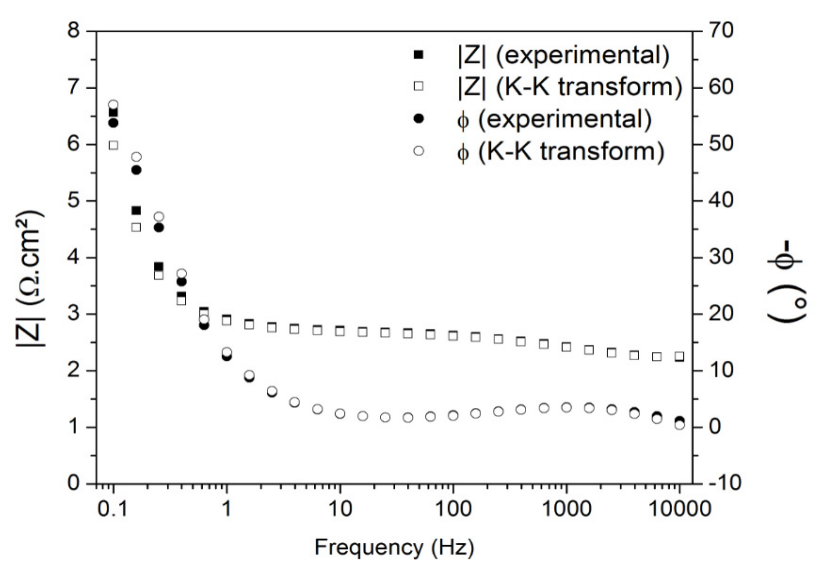

Figure 6: Bode diagram of both experimental and K-K transform plots of the horsemeat biosensor.

and the associated $\mathrm{K}-\mathrm{K}$ transform plots with respect to the magnitude of impedance $(|\mathrm{Z}|)$ and the phase angle $(-\phi)$. The curves are practically superimposed, which indicates the goodness of fit of the K-K transform to the experimental data, confirming that the biosensors developed for testing the sensitivity against horse serum and the selectivity against swine and bovine sera were not affected by external factors but only by changes in the electrode-electrolyte interface.

\section{Analysis of the sensitivity and selectivity of the biosensor to- wards horse serum in buffer solution}

The impedance data were interpreted with respect to the variation of $\mathrm{R}_{\mathrm{ct}}$ when the biosensor was exposed to horse, swine and bovine sera diluted at various concentrations in PBS buffer. $\Delta \mathrm{R}_{\mathrm{ct}}$ was calculated as the difference between the $\mathrm{R}_{\mathrm{ct}}$ obtained after and before the exposition of the biosensor to each serum solution.

As seen in the calibration plot (Figure 7), a progressive increase of $\mathrm{R}_{\mathrm{ct}}$ was observed only when the biosensor was exposed to its homologous (horse) serum, thus demonstrating the formation of the immunocomplex between the antigen (horse IgG) and the antibodies immobilized as units of recognition on the electrode surface. 


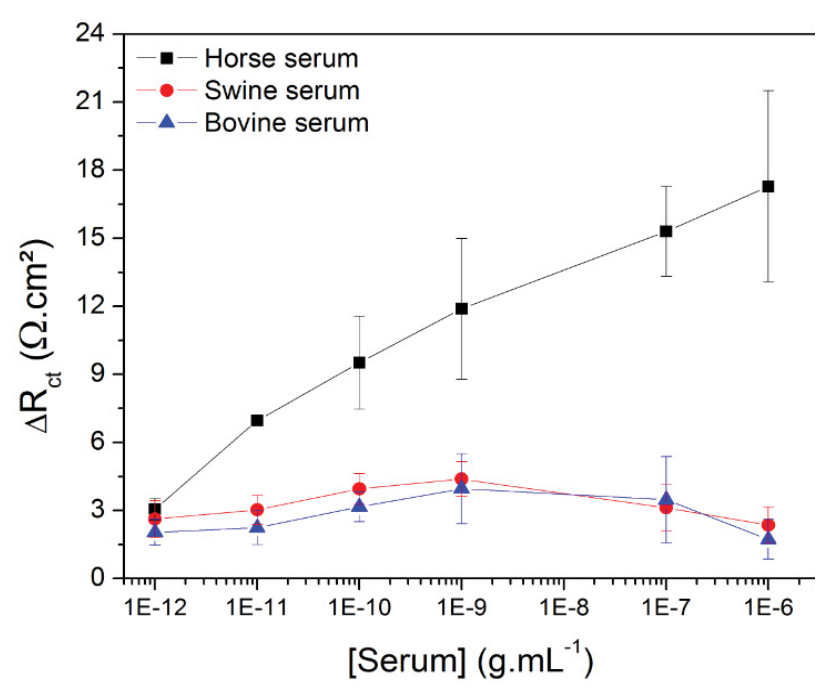

Figure 7: Calibration curve of the immunosensor exposed to horse, swine and bovine serum at various concentrations in PBS buffer.

The impedimetric immunosensor responded linearly towards the logarithm of the target analyte concentration, indicating that there is a strong relationship between the concentration of horse serum $\left[\mathrm{S}_{\text {horse }}\right]$ (g.mL $\left.{ }^{-1}\right)$ and the $\Delta \mathrm{R}_{\mathrm{ct}}\left(\Omega \cdot \mathrm{cm}^{2}\right)$ according to equation 4 .

$$
\Delta R_{\mathrm{ct}}=0.92266 \ln \left[S_{\text {horse }}\right]+30.32904
$$

Contrarily, when the heterologous swine and bovine sera were kept in contact with the electrode, a random variation of Rct was observed, which indicates there was no recognition of analyte in these solutions. A t-Student test with $95 \%$ confidence level revealed that there is no significant difference among the impedance increase of the immunosensor exposed to the horse serum at $10^{-12} \mathrm{~g} \cdot \mathrm{mL}^{-1}$ and to the swine $(\mathrm{p}=0.46)$ and bovine $(\mathrm{p}=0.07)$ sera at the same concentration. For this reason, the linearity of the impedimetric response was considered at the concentration range from $10^{-11}$ g.mL $\mathrm{mL}^{-1}$ to $10^{-6} \mathrm{~g} . \mathrm{mL}$ ${ }^{1}$. Table 1 presents the coefficients of logarithmic regression $\left(\mathrm{R}^{2}\right)$ with respect to the impedance response of the immunosensor exposed to horse, swine and bovine sera at the mentioned concentrations.

\section{Analysis of commercial meat samples}

For further evaluation of the biosensor, the recognition capability against the target analyte in real commercial raw meats was evaluated. The biosensor was exposed to solutions at unknown concentrations of horsemeat, pork and beef purchased from local market. After estimating the concentration of proteins in the commercial meat solutions at $1 \% \mathrm{w} / \mathrm{v}$ by UV-VIS spectroscopy, the following values were found: 3.44 x $10^{-4}$ g.mL $\mathrm{mL}^{-1}$ (horsemeat), $2.65 \times 10^{-4}$ g. $\mathrm{mL}^{-1}$ (pork) and $2.65 \times 10^{-4} \mathrm{~g} \cdot \mathrm{mL}$ ${ }^{1}$ (beef). The samples were diluted one thousand, ten thousand and a hundred thousand times before the exposure to the biosensor. Figure 8 presents the resultant impedance response of the biosensor reacted to real samples at the three concentrations.

The impedance data obtained by testing the biosensor against real sample of horsemeat were better adjusted to a linear regression plot following the equation $5\left(\mathrm{R}^{2}=0.9578\right)$, in which $\left[\mathrm{M}_{\text {horse }}\right]\left(\mathrm{g} \cdot \mathrm{mL}^{-1}\right)$ is the concentration of horsemeat.

$$
\Delta R_{\mathrm{ct}}=4.0 \times 10^{5}\left[M_{\text {horse }}\right]+0.25984
$$

The presence of interferers in the real samples, such as the nutritional components (fat, vitamins, inorganic salts, etc) probably affected the biosensor performance by preventing the target analyte to bind the units of recognition present in the electrode surface. The impedimetric response in real sample was lower than the ones obtained for all sera in buffer solution. This fact indicates that the meat components hinders the capability of the antibodies binding molecules independently whether they are the target analyte or unspecific compounds.

Concerning the time to perform the EIS test, to record the impedance measurement it was necessary $1.87 \pm 0.49 \mathrm{~min}$, which corresponds only to $3.37 \%$ of the total time related to the other steps (preparation of the meat sample, incubation period of the biosensor and OCP monitoring). Thus, the total time of approximately 72 min for performing the entire test could be consistently reduced by optimizing the protocol to extract the meat samples and/or the period of incubation in the analyte solution.

\section{Limit of detection (LOD) of the proposed immunosensor}

The LOD is defined as the lowest detectable concentration of an analyte in a sample. The resultant signal from the exposure to the analyte at the $\operatorname{LOD}\left(\mathrm{x}_{\mathrm{L}}\right)$ can be expressed as a function of the mean of the blank measurements $\left(\bar{x}_{b l}\right)$ and its standard deviation $\left(\sigma_{b l}\right)$ according to eq.6 [45], where " $k$ " is a factor equal to 3.3 related to the confidence level for estimating LOD [45].

$$
x_{L}=\bar{x}_{b l}+k \sigma_{b l}
$$

Based on the equations 4,5 and 6 , it was possible to estimate that the LOD of the immunosensor is $27.6 \mathrm{fg} \cdot \mathrm{mL}^{-1}$ towards the horse serum diluted in buffer solution and $1.54 \mu \mathrm{g} \cdot \mathrm{mL}^{-1}$ of horsemeat, which represents a percentage concentration of $0.004 \% \mathrm{w} / \mathrm{v}$ of proteins in horsemeat solution. This LOD is lower than those reported in the literature by detecting the presence of various species in meats using

\begin{tabular}{|c|c|c|c|}
\hline & Horse serum & Swine serum & Bovine serum \\
\hline $\mathrm{R}^{2}(-)$ & 0.995 & 0.0211 & 0.0126 \\
\hline
\end{tabular}

Table 1: $R^{2}$ value related to the logarithm fit of the correlation between $\Delta R_{c t}$ and concentration of horse, swine and bovine serum diluted in PBS buffer.

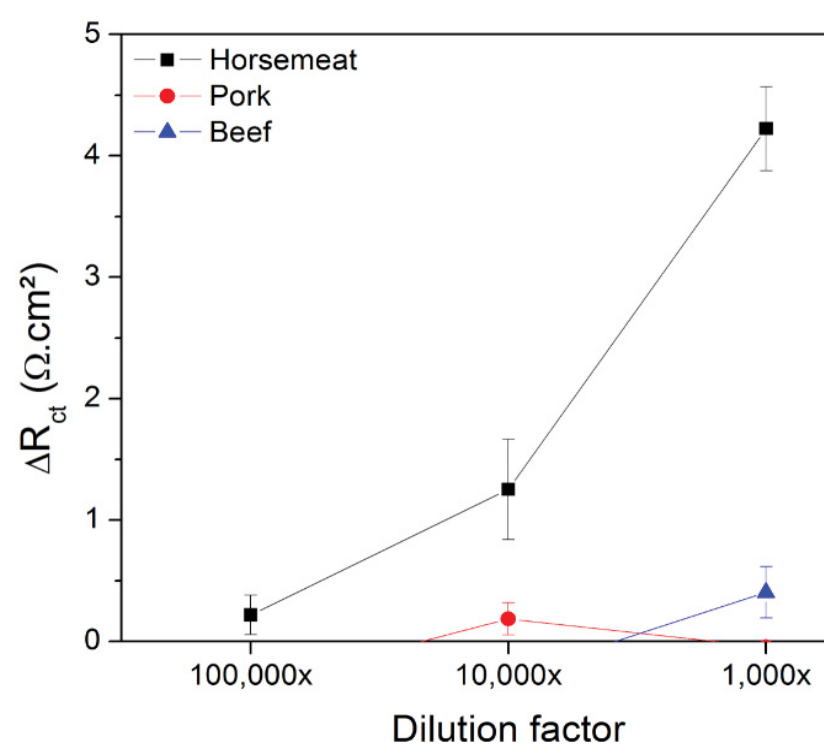

Figure 8: Calibration curve of the immunosensor exposed to horsemeat, pork and beef solutions diluted 1,000; 10,000 and 100,000 times. 
mass spectrometry (0.24\%) [46], ELISA (0.6 - 0.01\%) [47,48] and DNA-based assays $(0.1 \%)[49,50]$.

In order to consider adventitious presence of other species contaminants, the Food Standards Agency [51] considered that the products containing less than $0.1 \%$ of a mislabelled meat contaminant can be considered equivalent to zero (fraud absence). From 1\%, it should be considered the possibility of adulteration or negligence. Notwithstanding, the presence of beef or pork traces must be informed in the product label so as to protect religious faiths $[52,53]$.

\section{Conclusions}

This work reported the development of an impedimetric immunosensor for specific detection of horsemeat as a technology for screening meat adulteration. For this purpose, polyaniline electrodeposited on the surface of SPCEs served as the conductive matrix. CV and SEM/EDX analysis confirmed the functionalization of the polymeric transducer substrate by the immobilization of anti-horse IgG antibodies on the electrode surface. EIS technique was validated by using $\mathrm{K}-\mathrm{K}$ transform, which proved that the impedance data were consistent and stable. When exposed to horse serum diluted in PBS buffer, the developed immunosensors were very sensitive and selective exclusively towards the target analyte at various concentrations (with LOD equal to $\left.27.6 \mathrm{fg} . \mathrm{mL}^{-1}\right)$, not presenting significant variation of $\mathrm{R}_{\mathrm{ct}}$ to swine and bovine sera. The proposed device was also capable of recognizing the target analyte in real samples. The exposure to horsemeat at $10^{-5}, 10^{-4}$ and $10^{-3} \% \mathrm{w} / \mathrm{v}$ caused successive linear increases in the $R_{c t}$ due to the recognition of horse IgG in the samples. The immunosensor did not detect the presence of target analyte in commercial pork and bovine meat homogenates and presented a LOD of $0.004 \% \mathrm{w} / \mathrm{v}$. From the perspective of assay time, it was necessary approximately 70 minutes to perform the whole detection test, of which the obtaining of EIS data demanded only 3.37\%. To fully assess the real application of the proposed impedimetric immunosensor, future tests should focus on evaluating the effect of not only raw but also cooked meat on its performance, the stability of the sensor over long periods of storage and the presence of the target analyte as a contaminant at various concentrations in real samples.

\section{Acknowledgements}

The authors are thankful to Mir Pouyan Zarabadi from the group of Microfluidics and spectroscopy of materials of Université Laval and to Wagner Rafael Correr from the COPL for SEM measurement. This research was supported by the Natural Sciences and Engineering Research Council of Canada (CRSNG) and the Canada Excellence Research Chair in Photonics Innovations (CERCPI).

\section{References}

1. Moyer DC, DeVries J, Spink J (2017) The economics of a food fraud incident Case studies and examples including Melamine in Wheat Gluten. Food Control 71: 358-364.

2. Meira L, Costa J, Villa C, Ramos F, Oliveira MBPP, et al. (2017) EvaGreen real-time PCR to determine horse meat adulteration in processed foods. LWT - Food Science and Technology 75: 408-416.

3. Magiati M, Myridaki VM, Christopoulos TK, Kalogianni DP (2018) Lateral flow test for meat authentication with visual detection. Food Chem 274: 803-807.

4. Fuseini A, Wotton SB, Knowles TG, Hdley PJ (2017) Halal meat fraud and safety issues in the UK: a review in the context of the European Union. Food Ethics 1: 127-142.

5. Teixeira LV, Teixeira CS, Oliveira DAA (2015) Identificação espécieespecífica de carnes e produtos cárneos de origem bubalina e bovina pela técnica de PCR-RFLP. Arquivo Brasileiro de Medicina Veterinária e Zootecnia 67: 309-314.

6. Falkheimer J, Heide M (2015) Trust and Brand Recovery Campaigns in Crisis: Findus Nordic and the Horsemeat Scandal. Int J Strateg Commun 9: 134-147.
7. Arsalane A, Noureddine EB, Rhofir K, Tabyaoui A, Klilou A (2017) Beef and horse meat discrimination and storage time classification using a portable device based on DSP and PCA method. Int J Intell Enterp.

8. Danezis GP, Tsagkaris AS, Camin F, Brusic V, Georgiou CA (2016) Food authentication: techniques, trends \& emerging approaches. Trends in Analytical Chemistry 85 : 123-132.

9. Ottavian M, Fasolato L, Facco P, Barolo M (2013) Foodstuff authentication from spectral data: Toward a species-independent discrimination between fresh and frozen-thawed fish samples. J Food Eng 119: 765-775.

10. Kamruzzaman M, Makino Y, Oshita S (2016) Rapid and non-destructive detection of chicken adulteration in minced beef using visible near-infrared hyperspectral imaging and machine learning. J Food Eng 170: 8-15.

11. Ropodi AI, Panagou EZ, Nychas GJE (2017) Multispectral imaging (MSI): A promising method for the detection of minced beef adulteration with horsemeat. Food Control 73: 57-63.

12. Panagou EZ, Papadopoulou O, Carstensen JM, Nychas GJE (2014) Potential of multispectral imaging technology for rapid and non-destructive determination of the microbiological quality of beef filets during aerobic storage. Int $\mathrm{J}$ Food Microbiol 174: 1-11.

13. Kamruzzaman M, Makino Y, Oshita S, Liu S (2015) Assessment of Visible Near-Infrared Hyperspectral Imaging as a Tool for Detection of Horsemeat Adulteration in Minced Beef. Food Bioprocess Tech 8: 1054-1062.

14. Wen W, Yan X, Zhu C, Du D, Lin Y (2017) Recent advances in electrochemica immunosensors. Anal Chem 89: 138-156.

15. Xu R, Wei S, Zhou G, Ren J, Liu Z, et al. (2018) Multiplex TaqMan locked nucleic acid real-time PCR for the differential identification of various meat and meat products. Meat Sci 137: 41-46.

16. Singh PK, Jairath G, Ahlawat SS, Pathera A, Singh P (2016) Biosensor: an emerging safety tool for meat industry. J Food Sci Technol 53: 1759-1765.

17. Mehrotra P (2016) Biosensors and their applications - a review. J Oral Biol Craniofac Res 6: 153-159.

18. Sharma R, Deacon SE, Nowak D, George SE, Szymonik MP, et al. (2016) Label-free electrochemical impedance biosensor to detect human interleukin-8 in serum with sub-pg/ml sensitivity. Biosens Bioelectron 80: 607-613.

19. Kokkinos C, Economou A, Prodromidis MI (2016) Electrochemical immunosensors: Critical survey of different architectures and transduction strategies. Trends Analyt Chem 79: 88-105.

20. Pine Research (2016) Screen-printed electrode information. Carbon and ceramic electrode information, Pine research instrumentation, $\mathrm{Pp}: 1-10$.

21. Yukird J, Wongtangprasert $T$, Rangkupan R, Chailapakul O, Pisitkun T, et al. (2017) Label-free immunosensor based on graphene/polyaniline nanocomposite for neutrophil gelatinase-associated lipocalin detection. Biosens Bioelectron 87: 249-255

22. Promega (2018) Calculating nucleic acid or protein concentration. Using the GloMax® Multi+ Microplate Instrument.

23. Zhang L, Xiao J, Wang H, Shao M (2017) Carbon-based electrocatalysts for hydrogen and oxygen evolution reactions. ACS Catalysis 7: 7855-7865.

24. Qazi TH, Rai R, Boccaccini AR (2014) Tissue engineering of electrically responsive tissues using polyaniline based polyemers: a review. Biomaterials 35: 9068-9086.

25. Lai J, Yi Y, Zhu P, Shen J, Wu K, et al. (2016) Polyaniline-based glucose biosensor - a review. J Electroanal Chem 782: 138-153.

26. Chowdhury AD, De A, Chaudhuri CR, Bandyopadhyay K, Sen P (2012) Labe free polyaniline based impedimetric biosensor for detection of $\mathrm{E}$. coli $\mathrm{O} 157: \mathrm{H} 7$ bacteria. Sensors and Actuators B 171-172: 916-923.

27. Faria RAD, Lins VFC, Nappi GU, Matencio T, Heneine LGD (2018) Development of an impedimetric immunosensor for specific detection of snake venom. Bio Nano Science 8: 1-9.

28. Afkhami A, Hashemi P, Bagheri H, Salimian J, Ahmadi A, et al. (2017) Impedimetric immunosensor for the label-free and direct detection of botulinum neurotoxin serotype A using Au nanoparticles/graphene-chitosan composite. Biosens Bioelectron 93: 124-131.

29. Tsai JZ, Chen CJ, Settu K, Lin YF, Chen CL, et al. (2016) Screen-printed 
Citation: de Faria RAD, Iden H, Bharucha E, Lins VFC, Messaddeq Y et al. (2018) A New Tool for the Detection of Horsemeat Adulteration in Raw Meat. J Biosens Bioelectron 9: 264. doi: 10.4172/2155-6210.1000264

carbon electrode-based electrochemical immunosensor for rapid detection of microalbuminuria. Biosens Bioelectron 77: 1175-1182.

30. Bolado FP, Santos DH, Ardisana, PJL, Pernía AM, García AC (2008) Electrochemical characterization of screen-printed and conventional carbon paste electrodes. Electrochimica Acta 53: 3635-3642.

31. Obaid AY, El-Mossalamy EH, Al-Thabaiti SA, El-Hallag IS, Hermas AA, et al. (2014) Electrodeposition and Characterization of Polyaniline on Stainless Steel Surface via Cyclic, Convolutive Voltammetry and SEM in Aqueous Acidic Solutions. Int J Electrochem Sci 9: 1003-1015.

32. Mathebe NGR, Morrin A, Iwuoha EI (2004) Electrochemistry and scanning electron microscopy of polyaniline/peroxidase-based biosensor. Talanta 64 $115-120$

33. Reth M (2013) Matching cellular dimensions with molecular sizes. Nature Immunology 14: 765-767.

34. Saber R, Sarkar S, Gill P, Nazari B, Faridani F (2011) High resolution imaging of $\operatorname{lgG}$ and $\lg \mathrm{M}$ molecules by scanning tunneling microscopy in air condition. Scientia Iranica 18: 1643-1646.

35. Arkan E, Saber R, Karimi Z, Mostafaie A, Shamsipur M (2014) Multiwall carbon nanotube-ionic liquid electrode modified with gold nanoparticles as a base for preparation of a novel impedimetric immunosensor for low level detection of human serum albumin in biological fluids. J Pharm Biomed Anal 92: 74-81.

36. Liu Y, Yin F, Long Y, Zhang Z, Yao S (2003) Study of the immobilization of alcohol dehydrogenase on Au-colloid modified gold electrode by piezoelectric quartz crystal sensor, cyclic voltammetry, and electrochemical impedance techniques. J Colloid Interface Sci 258: 75-81.

37. Lasia A (2014) Electrochemical impedance spectroscopic and its applications. In Conway BE, Bockris JOM, White RE. Springer, New York.

38. Ramanathan M, Patil M, Epur R, Yun Y, Shanov V, et al. (2016) Gold-coated carbon nanotube electrode arrays: Immunosensors for impedimetric detection of bone biomarkers. Biosens Bioelectron 77: 580-588.

39. Gündoğdu A, Aydın EB, Sezgintürk MK (2017) A novel electrochemical immunosensor based on ITO modified by carboxyl-ended silane agent for ultrasensitive detection of MAGE-1 in human serum. Anal Biochem 537: 84-92.

40. Sharma A, Kumar A, Khan R (2017) Electrochemical immunosensor based on poly (3,4-ethylenedioxythiophene) modified with gold nanoparticle to detect aflatoxin B1. Materials Science and Engineering C 76: 802-809.
41. Osório WR, Garcia LR, Peixoto LC, Garcia A (2008) A influência da macrosegregação e da variação dos espaçamentos dentríticos na resistência a corrosão da liga Al-4,5\%Cu. Revista Matéria. Rio de Janeiro 13: 542-552.

42. Sarac AS, Ates M, Kilic B (2008) Electrochemical Impedance Spectroscopic Study of Polyaniline on Platinum, Glassy Carbon and Carbon Fiber Microelectrodes. Int J Electrochem Sci 3: 777-786.

43. Ates M, Sarac AS (2009) Electrochemical impedance spectroscopy of poly[carbazole-co-N-p-tolylsulfonyl pyrrole] on carbon fiber microelectrodes, equivalent circuits for modelling. Progress in Organic Coatings 65: 281-287.

44. Jinlong L, Hongyun L, Tongxiang $L$ (2016) Investigation of microstructure and corrosion behavior of burnished aluminum alloy by TEM, EWF, XPS and EIS techniques. Materials Research Bulletin 83: 148-154.

45. IUPAC (1997) Compendium of Chemical Terminology. (2nd ed), Blackwell Scientific Publications, Oxford.

46. Shrivastava A, Gupta VB (2011) Methods for the determination of limit of detection and limit of quantitation of the analytical methods. Chronicles of Young Scientists 2: 21

47. Von Bargen C, Brockmeyer J, Humpf HU (2014) Meat Authentication: A New HPLC-MS/MS Based Method for the Fast and Sensitive Detection of Horse and Pork in Highly Processed Food. J Agri and Food Chem 62: 9428-9435.

48. Mandli J, Fatimi IEL, Seddaoui N, Amine A (2018) Enzyme immunoassay (ELISA/immunosensor) for a sensitivite detectino of pork adulteration in meat Food Chemistry 255: 380-389.

49. Macedo-Silva A, Barbosa SFC, Alkmin MGA, Vaz AJ, Shimokomaki M, et al. (2000) Hamburguer meat identification by dot-ELISA. Meat Science 56 189-192.

50. Oliveira ACS, Pedroso SCS, Cardilli DJ, Leite JPL, Ferreira GVL, et al. (2018) Brazilian ground beef authentication by multiplex polymerase chain reaction. Ciência Rural 48: 1-7.

51. Chung HH (2018) Real-time polymerase chain reaction (RT-PCR) for the authentication of raw meats. Int Food Res J 25: 632-638.

52. Food Standards Agency (2010) European Commission's "Technical solution" to the low-level presence of unauthorized GMOs.

53. Premanandh J (2013) Horse meat scandal - A wake-up call for regulatory authorities. Food Control 34: 568-569. 